\title{
Total Laparoscopic Hysterectomy versus Total abdominal hysterectomy in Obese Patients
}

\author{
M.K.Alloush, M.A.Elsayed, W.M.Tawfik and N.F.Fekry \\ Obstetrics \& Gynecology, Dept., Faculty of Medicine, Benha Univ., Benha, Egypt \\ E-mail:Nessro.ness@gmail.com
}

\begin{abstract}
:
Background; Obesity is a health problem challenge in gynecologic operation. Laparoscopy has the possible benefits than abdominal hysterectomy of being faster, effective with low expected bleeding. Aim and objectives; was to make a comparison of the security, effectiveness and complications of laparoscopy hysterectomy and total abdomen hysterectomy in obesity cases. Patients and Methods; This randomized controlled report was performed at the Obstetrics \& Gynecology Dep., Benha University Hospitals, on 60 patients whom were allocated into 2 groups: (Group-I): 30 cases for total laparoscopic hysterectomy, (Group-II); 30 patients for trans-abdominal hysterectomy. Result: A highly significant change was found among the study groups regarding Haemorrhage, Fever, blood loss, $\mathrm{Hb} \%$, ileus duration and hospitalization. Conclusion: It is concluded that Patients managed by laparoscopic hysterectomy have significally lower incidence of blood loss, $\mathrm{Hb} \%$ decline, ileus duration and hospitalization than patients managed by total abdominal hysterectomy.
\end{abstract}

Keywords: Hysterectomy, Obesity, Total laparoscopic hysterectomy, total abdominal hysterectomy.

\section{Introduction}

One of the commonest accomplished surgeries is Hysterectomy. Though there are 3 methods in hysterectomy (open, vaginally and laparoscopically), still there are disagreements concerning the best way for accomplishing it.

Associated with it Obesity and risk-factors, are well recognized influences that negatively impact operative outcome. In obese patients Open hysterectomy has revealed to be correlated with elevated rates of sideeffects like wound infections and longer post-operative hospitalization [1].

Various gynecological comorbidities are related to obesity and overweight, and some of this need hysterectomy [e.g., endometrial cancer, benign indications like bleeding, fibroids, genital prolapses and endometrial hyper-plasia [2].

The total laparoscopic hysterectomy seems to be advantageous [e.g., had shorter operative time, more efficient, with lower blood loss] when compared to abdominal or vaginal hysterectomies' and is also more attainable in obese and nulliparous females [3].

In addition, laparoscopic hysterectomy [LH] had less perioperative comorbidities, shorter hospitalization duration and quicker return to the day ordinary activities in both obese and non-obese females. However, different studies revealed increased rate of abdominal hysterectomy $[\mathrm{AH}]$ with increased body mass index [BMI] [4].

Credit for the $1^{\text {st }}$ effective albeit non-planned abdominal sub-total hysterectomy was performed by Walter Burnham of Lowell, Massachusetts. The honor of the $1^{\text {st }}$ effective, planned sub-total abdominal hysterectomy for uterine fibroids was accomplished by another surgeon from Lowell, Massachusetts: Oilman Kimball [5].

Laparoscopic methods can be predominantly well suitable to obese case's operation as they could avoid the inadequate healing of surgery wounds and infections particularly when Diabetes mellitus (DM) is existing, and as well permit more rapid recovery and lesser hospitalization duration than open operation [6].

In spite of the operative benefits of laparoscopy, we wanted to discuss and assess the method of laparoscopy hysterectomy in obesity cases and its side-effects; and the influence of operative experience on the outcome and quality of life [7].

\section{Materials and Methods}

This study was a randomized controlled study carried at Obstetrics \& Gynecology department in Banha University from September 2020 till August 2021.

A total of 60 cases have been presented to history taking, clinical examinations, Lab examination, abdominal US and biopsy for doubtful pathology. Cases were allocated into 2 groups: GROUP (I) - 30 patients for total laparoscopic hysterectomy. GROUP (II) - 30 patients for transabdominal hysterectomy. Cases have been followed-up for 6-mths postoperatively. Data collection including surgical period, bleeding quantity, side-effects and hospitalization period.

Inclusion Criteria: Age above 40 years and below 40 years for highly indicated hysterectomy, BMI: $\geq 30.0$ $\mathrm{kg} / \mathrm{m} 2$, size of uterus $<14$ week of pregnancy size and indications for hysterectomy diagnosed with uterine benign diseases as uterine fibroids, adenomyosis, adnexal masses,,... etc.

Exclusion criteria: preceding abdomen operations and cardiac or breathing comorbidities inhibiting laparoscopic operation.

\section{Methods:}

History taking Personal history (age, marital status, parity, address, occupation and any special habits, Complaint of each woman in the study, Menstrual history: with emphasis on menstrual dating and regularity, Obstetric history: History of similar condition (recurrent abortion); number of abortions, induced or spontaneous, followed by surgical evacuation or not and if there was any post abortive complications, Contraceptive history: (Type \& duration) and Past history of any medical problem: as \{hypertention, 
diabetes mellitus and deep venous thrombosis (DVT)\}, history of blood intake, allergy to certain drugs and any previous operations including cesarean section (CS).

Clinical examination: Vital signs: BP, pulse and temp and Weight, height, BMI

Ultrasound evaluation: Size of uterus $<14$ week of pregnancy size. Detection of any uterine benign diseases as uterine fibroids, adenomyosis, adnexal masses,... etc.

Surgical details: Abdominal Hysterectomy (AH) was performed through pfannenstiel incision or lower midline incision.

Laparoscopic Hysterectomy (LH) was performed in low dorsal lithotomy position and vaginal examination under anesthesia after folly's catheter insertion then uterine manipulator has been located in uterine space (8).

Measured outcomes: surgical period was estimated from skin incision and final skin suture. Intraoperative blood loss is recorded. Hospitalization and analgesics given to the patients were recorded. Patient discharged to home after she can tolerate oral fluid with regular follow up at outpatient clinic for evaluation of delayed complications. Groups were compared as regard of ages mean, BMI, surgical period, estimated bleeding, complications rate, post-operative pain score and analgesic doses, postoperative hospitalization time and Convalescence time.

Statistical analysis: collected data was analyzed via SPSS-20 (IBM, USA). Quantitative variables have been presented as of mean and SD. Qualitative variables have been presented as numbers and percentage. For comparing parametric quantitative variables among 2 groups, Student t testing has been done. Qualitative variables comparison was done by means of chi-square $\left(\mathrm{X}_{2}\right)$ testing or Fisher's exact testing when frequencies less than 5. Pearson correlation coefficients have been utilized to evaluate the correlation among 2 variables with normal distribution. When a variable has no normal distribution, A result considered significant at $\mathrm{P}<0.05$.

Ethical faculty of committee: Permissions from the medicine ethical committee has been also obtained and approval from IRB was attained.

\section{Results}

A nonsignificant change was found among the study groups regarding history taking. (Table 1)

Table (1) Comparing among the study groups as regard history taking.

\begin{tabular}{|c|c|c|c|c|c|c|}
\hline \multirow[t]{2}{*}{ History taking } & \multicolumn{2}{|c|}{$\begin{array}{c}\text { Group-I (LH) } \\
(\mathbf{n}=\mathbf{3 0})\end{array}$} & \multicolumn{2}{|c|}{$\begin{array}{c}\text { Group-II (AH) } \\
(\mathbf{n}=\mathbf{3 0})\end{array}$} & \multirow[t]{2}{*}{$\begin{array}{l}\text { Test of } \\
\text { Sig. }\end{array}$} & \multirow[t]{2}{*}{$\mathbf{p}$} \\
\hline & No. & $\%$ & No. & $\%$ & & \\
\hline \multicolumn{7}{|l|}{ Age (years) } \\
\hline Min. - Max. & \multicolumn{2}{|c|}{$32.0-51.0$} & \multicolumn{2}{|c|}{$34.0-55.0$} & $t=$ & 0.315 \\
\hline Mean \pm SD & \multicolumn{2}{|c|}{$43.27 \pm 5.99$} & \multicolumn{2}{|c|}{$45.0 \pm 7.19$} & 1.014 & \\
\hline Median (IQR) & \multirow{2}{*}{\multicolumn{2}{|c|}{$43.5(38.25-48.0)$}} & \multicolumn{2}{|c|}{$47.0(37.0-50.75)$} & & \\
\hline \multicolumn{5}{|l|}{$\mathrm{BMI}\left(\mathrm{Kg} / \mathrm{m}^{2}\right)$} & & \\
\hline Min. - Max. & \multicolumn{2}{|c|}{$31.10-42.0$} & \multicolumn{2}{|c|}{$32.0-42.30$} & $t=$ & 0.478 \\
\hline Mean \pm SD. & \multirow{2}{*}{\multicolumn{2}{|c|}{$\begin{array}{c}36.65 \pm 3.30 \\
36.95(33.9-39.1)\end{array}$}} & \multirow{2}{*}{\multicolumn{2}{|c|}{$\begin{array}{c}37.27 \pm 3.35 \\
36.75(34.7-39.6)\end{array}$}} & 0.714 & \\
\hline \multirow{2}{*}{\multicolumn{7}{|c|}{ Parity }} \\
\hline & & & & & & \\
\hline Min. - Max. & \multirow{2}{*}{\multicolumn{2}{|c|}{$\begin{array}{c}1.0-5.0 \\
260+119\end{array}$}} & \multicolumn{2}{|c|}{$1.0-5.0$} & $\mathrm{U}=$ & 0.111 \\
\hline Mean \pm SD. & & & \multirow{2}{*}{\multicolumn{2}{|c|}{$\begin{array}{c}3.13 \pm 1.25 \\
3.0(2.0-4.0)\end{array}$}} & 345.0 & \\
\hline \multirow{2}{*}{\multicolumn{7}{|c|}{$\begin{array}{l}\text { Medan (IQR) } \\
\text { Previous abortion }\end{array}$}} \\
\hline & & & & & & \\
\hline No & 17 & 56.7 & 18 & 60.0 & $\gamma^{2}=$ & 0.793 \\
\hline Yes & 13 & 43.3 & 12 & 40.0 & 0.069 & \\
\hline \multicolumn{7}{|c|}{ History of drug intake } \\
\hline No & 30 & 100.0 & 30 & 100.0 & _- & _- \\
\hline Yes & 0 & 0.0 & 0 & 0.0 & & \\
\hline
\end{tabular}

$\chi^{2}$ : Chi square testing FE: Fisher Exact

t: Student t-testing U: Mann Whitney test

$\mathrm{p}$ : $\mathrm{p}$ value for comparison among the study groups

*: Statistical significance at $\mathrm{p}$ value $\leq 0.05$

\section{SD: Standard deviation IQR: Inter Quartile Range}

Group-I: $\quad$ Patient for total laparoscopic hysterectomy (TLH)

Group-II: patient for trans-abdominal hysterectomy (TAH)

A nonsignificant change was found among the study groups regarding ultrasound. (Table 2) 
Table (2) Comparing among the study groups as regard US.

\begin{tabular}{|c|c|c|c|c|c|c|}
\hline \multirow[t]{2}{*}{ US } & \multicolumn{2}{|c|}{$\begin{array}{c}\text { Group-I (LH) } \\
(\mathbf{n}=\mathbf{3 0})\end{array}$} & \multicolumn{2}{|c|}{$\begin{array}{c}\text { Group-II (AH) } \\
(\mathbf{n}=\mathbf{3 0})\end{array}$} & \multirow[t]{2}{*}{$\chi^{2}$} & \multirow[t]{2}{*}{$\mathbf{p}$} \\
\hline & No. & $\%$ & No. & $\%$ & & \\
\hline $\begin{array}{l}\text { Uterine size } \\
\text { <14 week }\end{array}$ & 30 & 100.0 & 30 & 100.0 & - & - \\
\hline Masses & & & & & & \\
\hline Uterine fibroids & 13 & 43.3 & 13 & 43.3 & 0.515 & 0.773 \\
\hline Adenomyosis & 12 & 40.0 & 10 & 33.3 & & \\
\hline Adnexal masses & 5 & 16.7 & 7 & 23.3 & & \\
\hline
\end{tabular}

$\chi^{2}$ : Chi square testing

$\mathrm{p}$ : $\mathrm{p}$ value for comparison among the study groups

*: Statistical significance at $p$ value $\leq 0.05$

Group-I: Patient for TLH

Group-II: patient for TAH.

A highly significant change was found among the study groups regarding Operative details. (Table 3)

Table (3) Comparing among the study groups as regard operative details

\begin{tabular}{lcccc}
\hline Operative details & $\begin{array}{c}\text { Group-I }(\mathbf{L H}) \\
(\mathbf{n = 3 0})\end{array}$ & $\begin{array}{c}\text { Group-II (AH) } \\
(\mathbf{n = 3 0 )}\end{array}$ & $\mathbf{t}$ & p \\
\hline Op. time (mins.) & $126.0-156.0$ & $99.0-138.0$ & $8.232^{*}$ & $<0.001^{*}$ \\
Min. - Max. & $141.4 \pm 8.62$ & $118.9 \pm 12.24$ & & \\
Mean + SD. & $142.5(135.0-149.0)$ & $120.5(108.0-131.0)$ & & \\
Median (IQR) & & & & \\
Blood loss (ml) & $60.0-200.0$ & $110.0-345.0$ & $7.814^{*}$ & $<0.001^{*}$ \\
Min. - Max. & $128.83 \pm 41.47$ & $239.17 \pm 65.27$ & & \\
Mean + SD. & $130.0(95.0-170.0)$ & $227.5(195.0-290.0)$ & & \\
Median (IQR) & & &
\end{tabular}

\section{t: Student t-testing}

$\mathrm{p}$ : $\mathrm{p}$ value for comparison among the study groups

*: Statistical significance at $\mathrm{p}$ value $\leq 0.05$

\section{SD: Standard deviation IQR: Inter Quartile Range}

Group-I: $\quad$ Patient for TLH

Group-II: patient for TAH.

A highly significant change was found among the study groups regarding Postoperative details. (Table 4)

Table (4) Comparing among the study groups as regard postoperative details.

\begin{tabular}{|c|c|c|c|c|}
\hline Postoperative details & $\begin{array}{c}\text { Group-I (LH) } \\
(\mathbf{n}=\mathbf{3 0})\end{array}$ & $\begin{array}{c}\text { Group-II (AH) } \\
(n=30)\end{array}$ & $\begin{array}{l}\text { Test of } \\
\text { Sig. }\end{array}$ & $\mathbf{p}$ \\
\hline \multicolumn{5}{|l|}{ Hb\% decline (gm/dl) } \\
\hline Min. - Max. & $0.10-1.70$ & $0.70-2.30$ & $\mathrm{U}=$ & $<0.001^{*}$ \\
\hline Mean \pm SD. & $0.86 \pm 0.46$ & $1.36 \pm 0.53$ & 213.0 & \\
\hline Median (IQR) & $0.80(0.50-1.10)$ & $1.20(1.0-1.70)$ & & \\
\hline \multicolumn{5}{|l|}{ Ileus duration (h) } \\
\hline Min. - Max. & $11.0-22.0$ & $15.0-31.0$ & $\mathrm{t}=$ & $<0.001^{*}$ \\
\hline Mean \pm SD. & $16.07 \pm 2.90$ & $22.0 \pm 4.84$ & $5.764^{*}$ & \\
\hline Median (IQR) & $16.0(14.0-17.0)$ & $21.0(19.0-26.0)$ & & \\
\hline \multicolumn{5}{|l|}{ Hospitalization (h) } \\
\hline Min. - Max. & $18.0-35.0$ & $89.0-144.0$ & $t=$ & $<0.001^{*}$ \\
\hline Mean \pm SD. & $27.43 \pm 5.91$ & $116.57 \pm 17.29$ & $26.715^{*}$ & \\
\hline Median (IQR) & $27.50(22.0-32.0)$ & $116.5(103.0-130.0)$ & & \\
\hline
\end{tabular}

\section{t: Student t-testing}

U: Mann Whitney testing

$\mathrm{p}$ : $\mathrm{p}$ value for comparison among the study groups

*: Statistical significance at $\mathrm{p}$ value $\leq 0.05$

SD: Standard deviation

Group-I: $\quad$ Patient for TLH Group-II: patient for TAH.

There were no patients with bowel injuries, bladder injury or vascular injury and a nonsignificant change was found among the study groups regarding Intra-operative Complications. (Table 5) 
Table (5) Comparing among the study groups as regard intraoperative complications

\begin{tabular}{|c|c|c|c|c|c|c|}
\hline \multirow[t]{2}{*}{$\begin{array}{l}\text { Intraoperative } \\
\text { Complications }\end{array}$} & \multicolumn{2}{|c|}{$\begin{array}{c}\text { Group-I (LH) } \\
\quad(n=30)\end{array}$} & \multicolumn{2}{|c|}{$\begin{array}{c}\text { Group-II (AH) } \\
(\mathbf{n}=\mathbf{3 0})\end{array}$} & \multirow[t]{2}{*}{$\chi^{2}$} & \multirow[t]{2}{*}{$\mathbf{p}$} \\
\hline & No. & $\%$ & No. & $\%$ & & \\
\hline \multicolumn{7}{|l|}{ Bowel injury } \\
\hline No & 30 & 100.0 & 30 & 100.0 & - & - \\
\hline Yes & 0 & 0.0 & 0 & 0.0 & & \\
\hline \multicolumn{7}{|l|}{ Bladder injury } \\
\hline No & 30 & 100.0 & 30 & 100.0 & - & - \\
\hline Yes & 0 & 0.0 & 0 & 0.0 & & \\
\hline \multicolumn{7}{|l|}{ Vascular injury } \\
\hline No & 30 & 100.0 & 30 & 100.0 & - & - \\
\hline Yes & 0 & 0.0 & 0 & 0.0 & & \\
\hline \multicolumn{7}{|l|}{ Transfusion } \\
\hline No & 26 & 86.7 & 20 & 66.7 & 3.354 & 0.067 \\
\hline Yes & 4 & 13.3 & 10 & 33.3 & & \\
\hline
\end{tabular}

$\chi^{2}$ : Chi square testing

$\mathrm{p}$ : $\mathrm{p}$ value for comparison among the study groups

*: Statistical significance at $\mathrm{p}$ value $\leq 0.05$

$\begin{array}{ll}\text { Group-I: } & \text { Patient for TLH } \\ \text { Group-II: } & \text { patient for TAH. }\end{array}$

A nonsignificant change was found among the study groups regarding Intraoperative Postoperative Complications. (Table 6)

Table (6) Comparing among the study groups as regard postoperative complications

\begin{tabular}{|c|c|c|c|c|c|c|}
\hline \multirow[t]{2}{*}{$\begin{array}{l}\text { Postoperative } \\
\text { Complications }\end{array}$} & \multicolumn{2}{|c|}{$\begin{array}{c}\text { Group-I (LH) } \\
(\mathbf{n}=\mathbf{3 0})\end{array}$} & \multicolumn{2}{|c|}{$\begin{array}{c}\text { Group-II (AH) } \\
\quad(\mathbf{n}=\mathbf{3 0})\end{array}$} & \multirow[t]{2}{*}{$\chi^{2}$} & \multirow[t]{2}{*}{${ }^{\mathrm{FE}} \mathbf{p}$} \\
\hline & No. & $\%$ & No. & $\%$ & & \\
\hline \multicolumn{7}{|l|}{ Haemorrhage } \\
\hline No & 30 & 100.0 & 30 & 100.0 & - & - \\
\hline Yes & 0 & 0.0 & 0 & 0.0 & & \\
\hline \multicolumn{7}{|l|}{ Fever } \\
\hline No & 28 & 93.3 & 26 & 86.7 & 0.741 & 0.671 \\
\hline Yes & 2 & 6.7 & 4 & 13.3 & & \\
\hline
\end{tabular}

$\chi^{2}$ : Chi square testing FE: Fisher Exact

$\mathrm{p}$ : $\mathrm{p}$ value for comparison among the study groups

*: Statistical significance at $\mathrm{p}$ value $\leq 0.05$

Group-I: Patient for TLH

Group-II: patient for TAH.

\section{Discussion}

Obesity increased the risk of cardiovascular and endocrinological diseases. In addition, various gynecological comorbidities are related to obesity and overweight, and some of this need hysterectomy [e.g., endometrial cancer, benign indications like blood loss disorders, fibroids, genital prolapses and endometrial hyper-plasia] [9].

Laparoscopic hysterectomy $[\mathrm{LH}]$ had less perioperative comorbidities; quicker hospitalizations duration and faster return to ordinary daily activity in both obese and non-obese females. However, different studies revealed increased rate of abdominal hysterectomy $[\mathrm{AH}]$ with elevated BMI [10]

This study revealed that a highly significant change was found among the study groups regarding Operative details.
Sesti et al. [11] found that laparoscopic

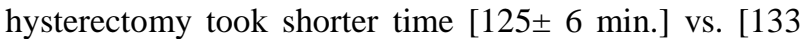
\pm 7 min.] for abdominal hysterectomy.

Similar to our results, Van Evert et al. [12] reported different results, where they reported that the operating time wasn't significantly dissimilar among the study groups.

The amount of bleeding was highly significant among the open hysterectomy group. This is in line with different previous trials where the estimated bleeding was significantly lower in LH compared to AH by Johns et al. [13] and Sesti et al. [11].

Lowell et al. [14] concluded different results, where they reported that laparoscopic hysterectomy had more estimated blood loss than abdominal hysterectomy this was attributed to the non-selection of specific criteria for cases for laparoscopic hysterectomy, they did not exclude large myomatus uteri reaching $500 \mathrm{gm}$. Van 
Evert et al. [12] also reported different results, where they reported that the bleeding wasn't significantly changed among the study groups.

Fathy et al. [8] found that mean surgical period was longer in group 1 than group 2 with statistical significance $(139 \pm 22$ minutes for laparoscopic hysterectomy compared to106 \pm 21 minutes for $\mathrm{AH}, \mathrm{p}<$ 0.001). Estimated bleeding wasn't significantly dissimilar in LH group $(184.8 \pm 214.69)$ compared to AH group $(208.75 \pm 234.23) \mathrm{P}=0.711$. There were two cases needed conversion to laparotomy.

Celik et al. [15[, Seracchioli et al. [16] and Ribeiro et al. [17] found that there was nonsignificant change about bleeding between LH and AH groups.

Uccella et al. [18] reported that median surgical period was extended in the LH group (120 vs. 85 minutes), whereas assessed bleeding were lesser between cases who were primarily managed by minimallyinvasive intervention.

Obermair et al. [19] found that the mean surgical period, estimated bleeding, bleeding $>500 \mathrm{~mL}$, and blood transfusions necessities were comparable in the two groups. While, the mean post-operative hospitalization was $4.4( \pm 3.9)$ days in the LH group and $7.9( \pm 3.0)$ days in the $\mathrm{AH}$ group $(\mathrm{P}, 0.0001)$

In this study a highly significant change was found among the study groups regarding Postoperative details.

The hospitalization period was very significant quicker among laparoscopic group. This agrees with Zhang et al. [20] found that postoperative hospitalizations after laparoscopic hysterectomy was significantly shorter in comparison to abdominal hysterectomy group. The shorter hospitalization with laparoscopic hysterectomy might be attributed to early ambulation associated with laparoscopic hysterectomy due to the small incision and the less postoperative pain and therefore short hospitalization which is considered a valuable advantage of $\mathrm{LH}$ method over $\mathrm{AH}$.

Sesti et al. [11] also found that postoperative hospitalization after LH was significantly shorter in comparison to $\mathrm{AH}$ group.

Fathy et al. [8] found that mean hospital stay was shorter for cases who managed by LH (group 1) than cases who experienced $\mathrm{AH}$ (group 2) with statistical significance $(2.22 \pm 0.95$ days compared to $5.52 \pm 6.91$ days, $\mathrm{p}=.022$ ).

Uccella et al. [18] reported that estimated bleeding, post-operative haemoglobin dropping and hospitalization (1 vs. 3 days) were lower between cases who were primarily managed by minimally-invasive intervention.

In this study there were no patients with bowel injuries, bladder injury or vascular injury and a nonsignificant change was found among the study groups regarding Intraoperative Complications.

Fathy et al. [8] found that one patient in each of groups had intraoperative bladder injury. There was no significant variance in the number of patients whom received blood transfusion but the number of transfused units of blood is more in laparoscopic hysterectomy group.
Ghezzi et al. [21] found that the two groups were comparable in the frequency of intra-operative sideeffects. Intra-operative side-effects happened in 4 cases, $3(8.1 \%)$ in the LAVH group and $1(2.8 \%)$ in the TLH group. One case in the LAVH group had a bladder injury throughout uterovesical fold incision, which was sutured by laparoscope. Reasonable subcutaneous emphysema happened at pneumoperitoneum formation in 1 female in the LAVH group. In the TLH group 1 case had moderate blood loss from the right port entry, which was handled by a trans parietal suture.

In the current work a nonsignificant change was found among the study groups regarding Intraoperative Postoperative Complications

Uccella et al. [18] found that the overall morbidities of minimal-invasive hysterectomy was lower, in comparison with open method as well in this sub-set of cases.

O'Hanlan et al. [22] found that nonsignificant change occurred in total complications rates for the $\mathrm{AH}$ or LH groups $(14 \%$ versus $5 \%$, Pvalue $=0.111)$ or in reoperative complications rates $(10$ versus $3 \%$, Pvalue $=0.128) .4$ side-effects happened in the AH group: 2 patients of wound dehiscence and 1 patient of postoperative haemorrhage necessitating re-operation, and 1 patient of post-operative wound infections handled with packing. Between the LH group, 1 patient each of trocar site herniation and small-bowel adhesions to the vaginal cuff resulting in small-bowel obstruction need reoperation.

We recognize some limitations in our study; the small sample size hinders the generalization of the results. Another point is the presence of confounding variable not unified in our study, which make the results subjected to bias, with consequent underestimation of possible adverse events. Further longitudinal studies in multicenter are needed to elucidate the clinical implications of our results. Also, future studies will provide both clinicians and researchers with new understandings for $\mathrm{LH}$ in obese patients, particularly those with morbid obesity.

\section{Conclusion}

Patients managed by laparoscopic hysterectomy have significantly lower incidence of blood loss, $\mathrm{Hb} \%$ decline, ileus duration and hospitalization than patients managed by total abdominal hysterectomy.

\section{References}

[1] P.Litta, AM.Fabris, E.Breda, C.Bartolucci, L.Conte, C.Saccardi. Laparoscopic surgical staging of endometrial cancer: does obesity influence feasibility and perioperative outcome? Eur J Gynaecol Oncol.vol. 34,pp.231-3,2013.

[2] F1.Morgan-Ortiz, JM.Soto-Pineda, MA.LópezZepeda, J.Peraza- Garay Fde. Effect of body mass index on clinical outcomes of patients undergoing total laparoscopic hysterectomy. Int J Gynaecol Obstet.vol. 120[1],pp.61-4, 2013. 
[3] DR.Scribner, JL.Walker, GA.Johnson, SD.Mcmeekin, MA.Gold, RS.Mannel. Laparoscopic pelvic and Para aortic lymph node dissection: analysis of the first 100 cases. Gynecol Oncol.vol.82,pp.498-503,2001.

[4] JW1.Aarts, TE.Nieboer, N.Johnson, E.Tavender, R.Garry, BW.Mol. Surgical approach to hysterectomy for benign gynecological disease. Cochrane Database Syst Rev.vol.[8],pp.CD003677,2015.

[5] TF. Baskett. Hysterectomy: evolution and trends. Best Practice Res Clin Obstetrics Gynaecol.vol.19(3),pp.295-305,2005.

[6] KJ.Matthews, E.Brock, SA.Cohen, D.Chelmow. Hysterectomy in obese patients: special considerations. Clin Obstet Gynecol,vol.57,pp.106-14, 2014.

[7] B.Geppert, C.Lonnerfors, J.Persson. Robotassisted laparoscopic hysterectomy in obese and morbidly obese women: surgical technique and comparison with open surgery. Acta Obstet Gynecol Scand.vol. 90,pp.1210-7,2011.

[8] M.Fathy, H.Al-Azony, E.Hasanen, N.AbdElhamid. Total laparoscopic hysterectomy versus total abdominal hysterectomy in uterine tumors. The Egyptian Journal of Hospital Medicine.vol. 72(10),pp. 5427-5432, 2018.

[9] M.M.Kaur, T.Ind. Laparoscopic and robotic surgery in obese women. In Obesity and Gynecology.vol.8,pp.223-243,2020.

[10] A.Orhan, K.Ozerkan, I.Kasapoglu, G.Ocakoglu, BC.Demir, T.Gunaydin. Laparoscopic hysterectomy trends in challenging cases (19952018). Journal of gynecology obstetrics and human reproduction.vol. 48(10),pp. 791$798,2019$.

[11]F.Sesti, V.Ruggeri, A .Pietropolli, E. Piccione. Laparoscopically assisted vaginal hysterectomy versus vaginal hysterectomy for enlarged uterus. JSLS: Journal of the Society of Laparoendoscopic Surgeons.vol.12(3),pp. 246, 2008.

[12] JS.Van Evert, JM. Smeenk, F.Dijkhuizen, J. De Kruif K. Kluivers. Laparoscopic subtotal hysterectomy versus laparoscopic total hysterectomy: a decade of experience. Gynecological surgery.vol. 7(1),pp. 9$12,2010$.

[13]D. Johns, R .Ferland, R. Dunn. Initial feasibility study of a sprayable hydrogel adhesion barrier system in patients undergoing laparoscopic ovarian surgery. The Journal of the American Association of Gynecologic Laparoscopists.vol. 10(3),pp. 334-338,2003.

[14]L. Lowell, \& A. Kessler. Laparoscopically assisted vaginal hysterectomy. A suitable substitute for abdominal hysterectomy?. The Journal of reproductive medicine.vol. 45(9), pp.738-742,2000.
[15]C.Celik, R.Abali, N.Tasdemir, E.Aksu, H.Calıskan, D.Akkus. Total Laparoscopic Hysterectomy Compared with Abdominal Hysterectomy; Clinical Outcomes. J Clin Anal Med.vol.5(6),pp.490-3,2014.

[16] R.Seracchioli, S.Venturoli, F.Vianello, F.Govoni, M.Cantarelli, Be.Gualerzi. Total laparoscopic hysterectomy compared with abdominal hysterectomy in the presence of a large uterus. J Am Assoc Gynecol Laparosc.vol. 9 (3),pp.3338,2016.

[17] S.Ribeiro, R.Ribeiro, N.S antos, J.Pinotti. A randomized study of total abdominal, vaginal and laparoscopic hysterectomy. Int $\mathbf{J}$ Gynaecol Obstet.vol. 83(1),pp.37-43, 2003.

[18] S.Uccella, C.Morosi, N.Marconi, A.Arrigo, B.Gisone, J.Casarin. Laparoscopic versus open hysterectomy for benign disease in uteri weighing > $1 \mathrm{~kg}$ : a retrospective analysis on 258 patients. Journal of minimally invasive gynecology.vol. 25(1),pp. 62-69, 2018.

[19] A.Obermair, T.Manolitsas, Y.Leung, I.Hammond, A.McCartney. Total laparoscopic hysterectomy versus total abdominal hysterectomy for obese women with endometrial cancer. International Journal of Gynecologic Cancer.vol. 15,pp.(2), 2005.

[20] Y.Zhang, E.Lee, L.Cowan, K.North, R.Wild, B.Howard. Hysterectomy prevalence and cardiovascular disease risk factors in American Indian women. Maturitas.vol.52(3-4), pp.328336,2005 .

[21]F.Ghezzi, A.Cromi, V.Bergamini, S.Uccella, P.Beretta, M.Franchi. Laparoscopic-assisted vaginal hysterectomy versus total laparoscopic hysterectomy for the management of endometrial cancer: a randomized clinical trial. Journal of Minimally Invasive Gynecology.vol.13(2),pp. 114-120,2006.

[22] K.O'Hanlan, G.Huang, A.Garnier, S .Dibble, M. Reuland, L. Lopez. Total laparoscopic hysterectomy versus total abdominal hysterectomy: cohort review of patients with uterine neoplasia. JSLS: Journal of the Society of Laparoendoscopic Surgeons.vol. 9(3),pp. 277,2005 . 